\title{
Delayed Presentation of Rectal Trauma - Is Colostomy Necessary?
}

\author{
Basim Al Khafaji ${ }^{1}$, Muhammad Umar Younis ${ }^{2}$, Yousif Al Khafaji ${ }^{1}$ \\ ${ }^{1}$ Department of Surgery, Canadian Specialist Hospital Dubai, UAE; ${ }^{2}$ Hospitalist General Surgery, Mediclinic City Hospital \\ Dubai, UAE.
}

\section{Corresponding Author: \\ Dr Muhammad Umar Younis \\ Email: umar000@hotmail.com}

This is an Open Access article distributed under the terms of the Creative Commons Attribution License (creativecommons.org/ licenses/by/3.0).

\begin{abstract}
Background: Presentation of rectal injuries in the civilian setting is often delayed due to patient denial or assault and requires a high index of suspicion for diagnosis. The standard of care in dealing with such injuries has evolved from mandatory fecal diversion to emphasis on avoidance of colostomy whenever possible. Case Report: A 17 year old male presented to the emergency department with complaints of severe lower abdominal pain, high grade fever and bloody stool following a fall at swimming facility. CT scan abdomen and pelvis confirmed presence of a well organized hematoma in right side of vesicorectal pouch with no active leak. Proctoscopy under anesthesia confirmed rectal perforation on the anterior wall on the right side and a small ulcer after blood clots were evacuated. This was sutured in the same setting and patient was kept on oral liquids and responded well to treatment with follow up ultrasound scans confirming reduction in hematoma size. He was discharged on $7^{\text {th }}$ day and remained healthy on immediate follow up. Conclusion: Primary repair of low rectal perforation during proctoscopy under anesthesia can be safely carried out without colostomy as an alternative in patients presenting with hemodynamic stability and limited sepsis. The optimum approach should be individualized and fecal diversion should be avoided where possible to reduce morbidity.
\end{abstract}

Keywords: Abdomen, Colostomy, Hematoma, Pelvis, Proctoscopy, Rectum, Ulcer.

\section{Introduction}

Rectal injuries are infrequent events in clinical practice due to the protection provided by its relative position in the bony pelvis. While rectal injury can occur by itself or in association with a colon injury, it is reported to occur in $1.1 \%$ of trauma patients out of which $80 \%$ are due to penetrating trauma [1]. Presentation with such injuries in the civilian setting is often delayed due to patient denial or assault and requires a high index of suspicion for diagnosis. The standard of care in dealing with such injuries has evolved from mandatory fecal diversion during wartime to emphasis on avoidance of colostomy whenever possible [2]. Factors influencing management strategy include injury grade, fecal contamination, anal sphincter involvement, associated injuries and type of trauma [3]. We discuss here a case of blunt rectal trauma which presented to us with a delay of 72 hours and was dealt with transanal primary repair without diversion colostomy.

\section{Case Report}

A 17 year old male presented to the emergency department with complaints of severe lower abdominal pain, high grade fever and bloody stool. He described a history of fall at a swimming pool with loss of consciousness 3 days earlier and was taken to a nearby hospital. He complained of hematuria and underwent $\mathrm{CT}$ scan head as well as $\mathrm{CT}$ abdomen and pelvis with intravenous (IV) contrast. The results came back normal for 
CT head but showed an ill-defined hematoma in the vesicorectal pouch in the pelvic images. He was observed overnight there and discharged on request the next day once the hematuria cleared up. He remained well at home initially but subsequently developed high grade fever with chills and bloody stools and attended our hospital for further management. Hence, the presentation to our facility was delayed by an interval of 72 hours.

Examination at the time of admission revealed marked tenderness and guarding in the suprapubic region along with high inflammatory markers $\left(\mathrm{TLC}=15.73 \times 10^{9} / \mathrm{L}, \mathrm{CRP}=285.65\right.$ $\mathrm{mg} / \mathrm{L})$. An immediate CT scan abdomen and pelvis was ordered with IV and rectal contrast that confirmed presence of a well organized hematoma $6.2 \times 3.6 \times 3.4 \mathrm{~cm}$ in right side of vesicorectal pouch with no active leak along with a thin hyperdense streak in right side of sigmoid colon with a suspicion of sealed off rectal perforation; clear fat planes were observed with rectal wall and bladder wall [Fig.1-3].

Patient was admitted and kept nil per oral and intravenous antibiotics started. Fever and bleeding per rectum persisted and he underwent proctoscopy under anesthesia which confirmed low rectal perforation on the anterior wall on the right side and a small ulcer after blood clots were evacuated. This was sutured through transanal approach in the same setting and patient was kept on oral liquids with gradual addition of a low residue diet over the next few days which he tolerated well. Follow up ultrasound scans done during hospitalization confirmed decrease in hematoma size upto $4 \times 1.2 \mathrm{~cm}$ and blood tests normalized to $\mathrm{TLC}=6.31 \times 10^{9} / \mathrm{L}$ and CRP came down to $29.53 \mathrm{mg} / \mathrm{L}$. Another proctoscopy was done before discharge which confirmed sufficient healing of the defect and he was discharged on $7^{\text {th }}$ day and remained healthy on outpatient follow up till 6 months with complete uneventful resolution of the pelvic hematoma.

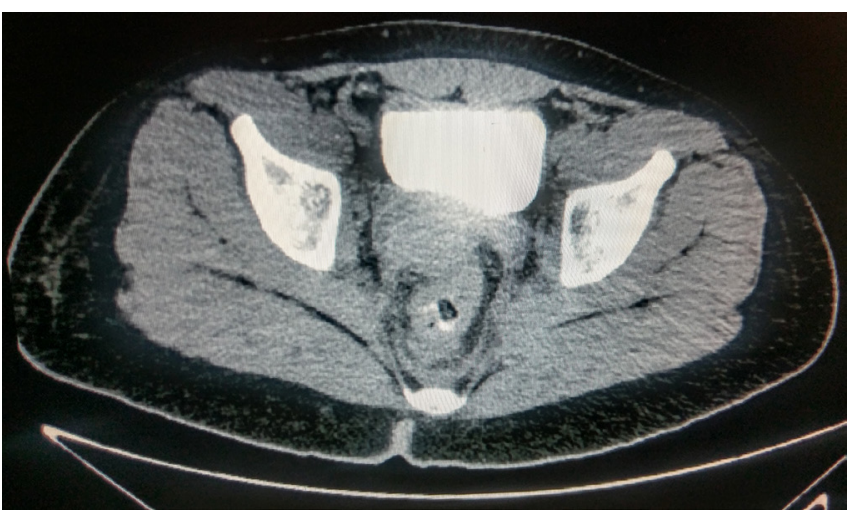

Fig.1: Axial CT scan abdomen depicting hematoma.

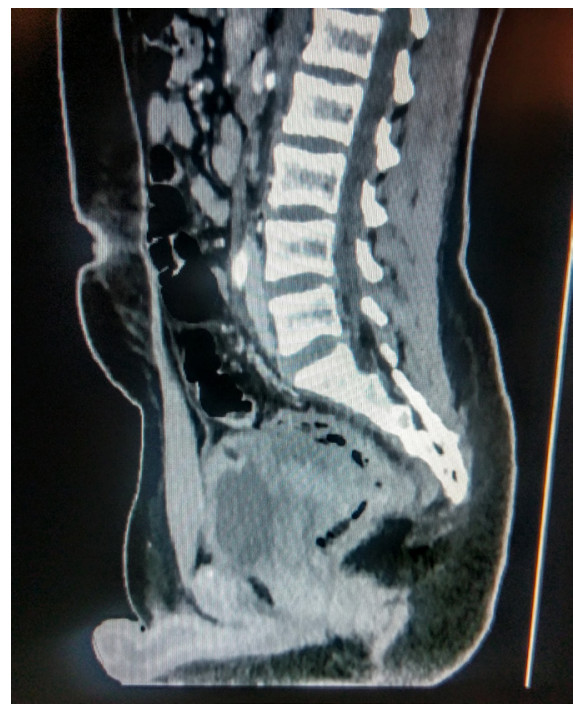

Fig.2: Sagittal CT scan abdomen without contrast.

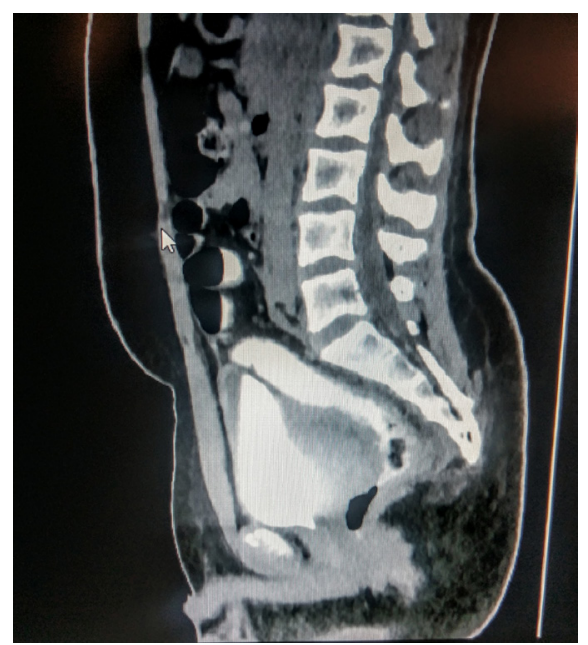

Fig.3: Sagittal CT scan abdomen with contrast. 


\section{Discussion}

The approach to management of rectal trauma has largely been influenced by experience amassed from war-time high energy penetrating injuries, the fundamental principles of which included fecal diversion, presacral drainage, distal rectal washout and primary repair if possible [4]. However, presentation in the civilian setting is distinct due to prevalence of low-energy injuries and is quite often delayed as well due to patient denial and embarrassment or assault which may require a high index of suspicion to clinch the diagnosis. Blunt abdominal trauma is more common in civilian cases as well and may lead to extra-peritoneal rectal injuries which have high complication rates of 20 $70 \%$ due to association with fractures involving the bony pelvis [2].

Intra-peritoneal rectal perforations usually require a diverting colostomy in addition to primary repair of injury [5]. On the contrary, treatment of extra-peritoneal rectal injuries do not have a standardized approach and the decision to perform a repair with or without fecal diversion depends on various factors like site of injury, cause and grade of injury, physiological condition of the patient and antibiotic use [6,7]. Selected patients can be repaired obviating the need for stoma [8], and can be attempted transanally if possible as described in a series carried out by Levine et al. [9] who repaired 5 cases of extra-peritoneal rectal injuries transanally without fecal diversion with no subsequent morbidity. Transanal repairs can be done with full thickness suturing if accessible as in our presented case, or endoscopic hemoclips can be used to close the defect satisfactorily [10]. Our report lends credence to the fact that stoma can be avoided in selected patients showing no signs of hemodynamic instability or sepsis and broad spectrum antibiotics should be instituted early on in the management of such a case.

\section{Conclusion}

Primary repair of low rectal perforation during proctoscopy under anesthesia can be safely carried out without colostomy as an alternative in patients presenting with hemodynamic stability and limited sepsis. The optimum approach should be individualized and fecal diversion should be avoided where possible to reduce morbidity.

Contributors: BAK: manuscript editing and patient management; MUY: manuscript writing and patient management; YAK: critical inputs into the manuscript and literature search. MUY will act as a study guarantor. All authors approved the final version of this manuscript and are responsible for all aspects of the study.

Funding: None; Competing interests: None stated.

\section{References}

1. Navsaria PH, Edu S, Nicol AJ. Nonoperative management of pelvic gunshot wounds. Amer J Surg. 2011;201:784-788.

2. Choi WJ. Management of colorectal trauma. J Korean Soc Coloproctol. 2011;27(4):166-173.

3. Joe D. Colonic trauma: indications for diversion vs repair. J Gastrointest Surg. 2009;13(3):403-404.

4. Tanzeela G, Noman S, Ahmed IE, Fareed AS, Hasnain $Z$. Fifteen years experience of managing penetrating extra-peritoneal rectal injuries. Surg Med Open Acc J. 2018;1(4). SMOAJ.000520.2018.

5. O'Donnell MT, Greer LT, Nelson J, Shriver C, Vertrees A. Diversion remains the standard of care for modern management of war related rectal injuries. Mil Med 2014;179:778-782.

6. Joe D. Colonic trauma: indications for diversion vs repair. J Gastrointest Surg. 2009;13(3):403-404.

7. Papadopoulos VN, Michalopoulos A, Apostolidis S, Paramythiotis D, Ioannidis A, Mekras A, et al. Surgical management of colorectal injuries: colostomy or primary repair? Tech Coloproctol. 2011;15(suppl 1):S63-S66.

8. Gumus M, Kapan M, Onder A, Boyuk A, Girgin A, Tacyildiz I. Factors affecting morbidity in penetrating rectal injuries: a civilian experience. Ulus Travma Acil Cerrahi Derg. 2011;17(5):401-406.

9. Levine JH, Longo WE, Pruitt C, Mazuski JE, Shapiro MJ, Durham RM. Management of selected rectal injuries by primary repair. Am J Surg. 1996;172(5):575-579.

10. Hahn KY, Ko SY, Lee WS, Kim YH. Extraperitoneal rectal laceration secondary to blunt trauma: Successful transanal endoscopic repair with hemoclips. Chin Med J. 2017;130:2384-2385. 